\title{
Los Desafíos a la Gobernabilidad Democrática en América Latina ${ }^{1}$ \\ *Por Carlos Tünnermann
}

Recibido: 17 de enero de 2011 / Aceptado: 02 de mayo de 2011.

\section{RESUMEN}

Carlos Tünnermann, parte de una breve puntualización sobre el concepto de gobernabilidad democrática, destacando componentes esenciales como: buen gobierno, estado de derecho, participación y cohesión social; sin embargo, incorpora otros factores que enriquecen y consolidan la concepción y el debate actual sobre el tema: la capacidad de los gobiernos democráticos para atender las demandas fundamentales de la población; la necesaria refundación del Estado, en el marco de las nuevas exigencias que impone la globalización extrema y la descentralización y regionalización interna; la participación de actores como la sociedad civil y la fundamentación ética de la política, entendida la ética "no sólo como un conjunto de principios y valores sino como un elemento dinámico, sensibilizador del comportamiento político de nuestros pueblos.

\section{ABSTRACT}

A brief explanation on concept of democratic Governability is offered by Carlos Tünnermann, emphasizing essential elements, such as: good Government, democracy, social participation and coherence; apart from that, there are others that enrich the current debate on theme: ability of democratic governments to respond the fundamental demands of population; necessary refoundation of State, within the framework of new demands imposed by extreme globalization and internal decentralization and regionalization; civil society participation and ethical base of politics.

Keywords: democratic government, State, civil society, satisfied needs.

Palabras clave: gobernabilidad democrática, estado, sociedad civil, necesidades satisfechas.

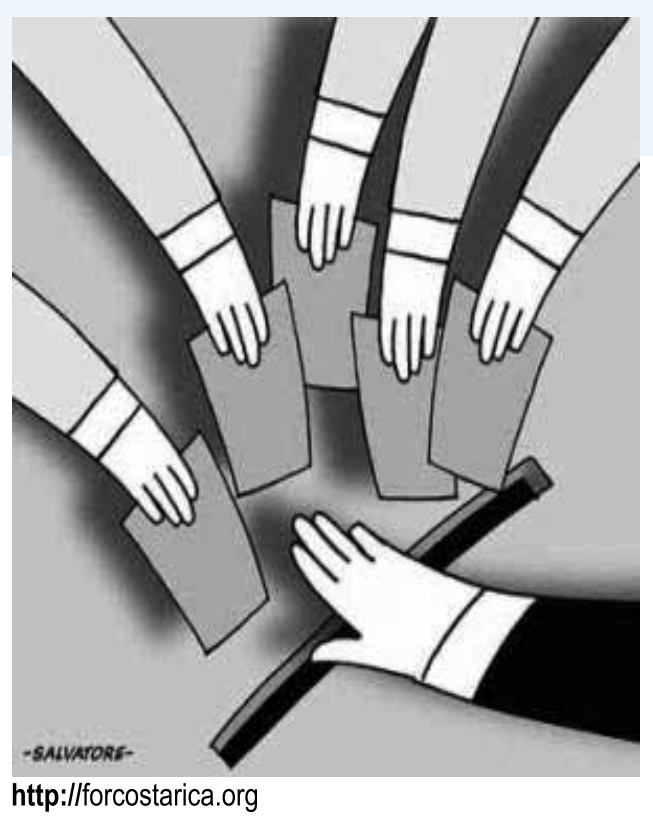

* Pedagogo y escritor nicaragüense. 


\section{El concepto de gobernabilidad democrática.}

El concepto de gobernabilidad democrática es un concepto complejo, desde luego que alude no solo a la idea de estabilidad, sino que es algo más: se refiere al modo de ejercer el poder, a su ejercicio democrático y no autoritario, y a la administración de un país encaminada a propiciar su desarrollo humano y sostenible. Hoy día, como señalan los analistas, el debate sobre la gobernabilidad democrática ocupa un lugar central en la reflexión política que serelaciona con el perfeccionamiento de la funcionalidad de las instituciones.

Carlos Mateo Balmelli, en su ensayo sobre el tema, publicado por la Fundación Konrad Adenauer, sostiene que "el fenómeno de la gobernabilidad no debe ser reducido únicamente a los problemas de estabilidad política. Las políticas de gobernabilidad apuntalan el esfuerzo colectivo al logro de un ambiente político estable. Solamente en un escenario institucional previsible en lo jurídico y en lo político, es factible realizar prácticas políticas que conduzcan al mejoramiento de la calidad de la convivencia. La gobernabilidad, en una de sus dimensiones, consiste en crear las condiciones para la acción del buen gobierno" ${ }^{11}$.

En una conferencia dictada el 31 de mayo del año 2000 en Managua, el entonces Representante Residente de las Naciones Unidas, don Carmelo Angulo expresó que "en el Programa de las Naciones Unidas para el Desarrollo (PNUD), definimos la Gobernabilidad como la suma de valores, leyes y reglas del juego de las que cada país se dota para resolver de manera pacífica y constructiva los problemas que puedan surgir entre las instituciones del Estado, el gobierno y los ciudadanos, así como entre estos mismos. La gobernabilidad comprende complejos mecanismos, procesos e instituciones a través de los cuales las personas articulan sus intereses, resuelven sus diferencias y ejercen sus derechos y obligaciones legales y personales. Aunque la gobernabilidad incluye al Estado, ésta lo trasciende al incluir también al sector privado y a las otras expresiones de la sociedad civil". Y continuó, la gobernabilidad democrática tiene, al menos, cuatro grandes componentes:

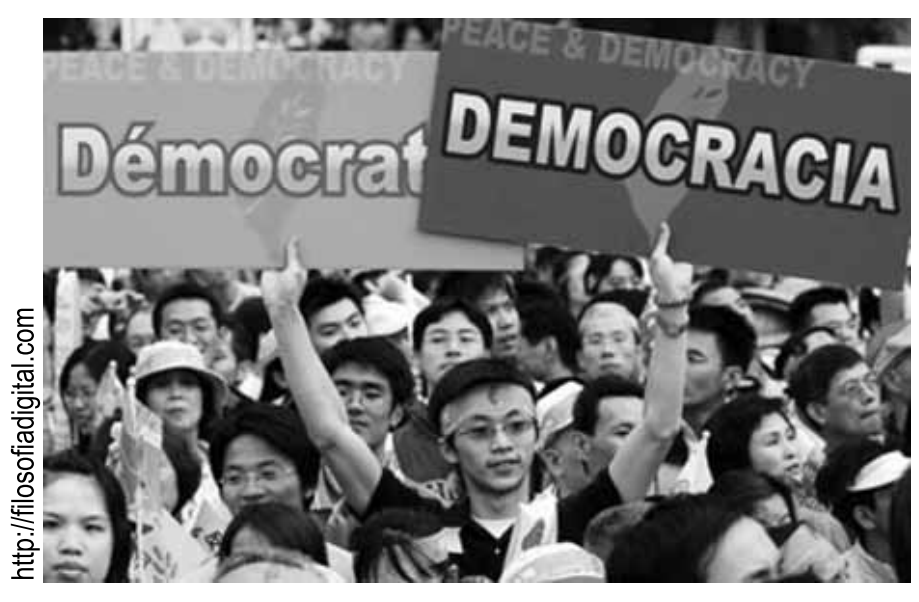

Buen gobierno: Se refiere a la transparencia, la claridad y la coherencia de los objetivos políticos, la buena gestión de los recursos económicos y medioambientales, la promoción de la equidad en el acceso a los mismos y la participación de los distintos sectores de la sociedad en las grandes decisiones. Estos principios otorgan una dirección estratégica al país y constituyen la base de la confianza entre gobernados y gobernantes.

Estado de derecho: Está basado en un correcto equilibrio entre los distintos poderes del Estado. El respeto a la ley y la aplicación igualitaria de la justicia para toda la ciudadanía son sus principales características.

Participación: Se requiere superara la visión limitada de la democracia como el sólo ejercicio electoral. La participación de los diferentes actores de la sociedad civil pasa por su involucramiento en los procesos económicos, sociales y políticos, asumiendo corresponsabilidad en la solución de los problemas y un papel beligerante en los procesos de control y auditoría social.

Cohesión social: Su búsqueda conduce a la justicia social, a la superación de la marginación de importantes sectores sociales, a la salvaguarda de los derechos de las minorías y a la protección e inclusión de los grupos llamados "vulnerables", que enfrentan limitaciones porque no tienen las mismas oportunidades que el resto de la sociedad (indígenas, mujeres, niños, jóvenes, discapacitados, etc.)"2.

1 Carlos Mateo Balmelli: Gobernabilidad Democrática, Fundación Konrad Adenauer, Asunción, Paraguay, 1998.

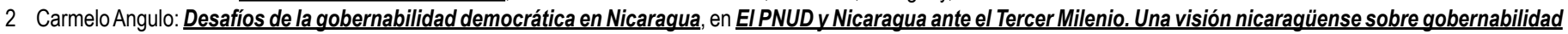
y desarrollo humano, PNUD, 2001. 
La gobernabilidad democrática es, pues, el resultado de una sinergia en la cual intervienen una serie de elementos $\mathrm{y}$ prerrequisitos que deben darse en una sociedad. Pero, no existe una fórmula mágica ni preestablecida. Sin embargo, la gobernabilidad demanda el ejercicio pleno de la democracia como condición necesaria aunque no suficiente. Se requiere, además, la vigencia de ciertos valores claves, como la justicia, la libertad, la solidaridad, la transparencia, la participación y la responsabilidad ciudadana, mayor nivel de cultura política; entre otros. No hay gobernabilidad sin la interacción de todos los sectores sociales, que deben compartir el sentimiento de que sus demandas están, o pueden llegar a estar, razonablemente satisfechas.

Una sólida gobernabilidad democrática se asienta sobre la existencia de grandes consensos políticos y sociales. Hay quienes estiman que la idea de acuerdo, de consenso, es inherente a la definición de la gobernabilidad democrática. Algunos consideran que la puerta de entrada a la gobernabilidad democrática es la estabilidad política, resultado de una constelación de factores políticos, económicos y sociales. La gobernabilidad suele también asociarse, en el debate contemporáneo, con el desarrollo. Se dice así que en un país si no hay gobernabilidad no hay desarrollo y viceversa, si no hay desarrollo no hay gobernabilidad, pues las demandas insatisfechas generan tensión social e inestabilidad.

Sin duda, una relación armoniosa y respetuosa entre los poderes del Estado contribuye a generar estabilidad y a propiciar la gobernabilidad. Pero, no basta ese equilibrio entre los poderes del Estado. También se requieren relaciones constructivas con la sociedad civil organizada, que permitan fundamentar las políticas de largo plazo sobre amplios consensos nacionales. Un escenario de tal naturaleza fortalece la legitimidad de las instituciones políticas frente a la sociedad.

Según Fernando Carrillo Flórez, en su ensayo sobre el déficit de la democratización en América Latina, existe toda una constelación de déficits que desafían a la gobernabilidad democrática. Carrillo Flórez enumera los siguientes:
- El déficit del constitucionalismo democrático.

- El déficit de institucionalización democrática.

- El déficit de lo público.

- El déficit de ética pública.

- El déficit de equidad.

- El déficit de protección de derechos.

- El déficit de justicia.

- El déficit de seguridad ciudadana.

- El déficit de ciudadanía.

- El déficit de liderazgo político.

- El déficit de representación.

- El déficit parlamentario.

- El déficit de capital social.

- El déficit de cultura política ${ }^{3}$.

De ahí que algunos autores concluyan que la legitimidad del gobierno y de los partidos políticos ante la sociedad, la relación eficiente y armoniosa entre los poderes del Estado, la distribución de la riqueza con justicia social, la descentralización política y económica y los espacios de participación ciudadana en el quehacer local y nacional, son factores de estabilidad, de afianzamiento democrático $\mathrm{y}$, por consiguiente, de una apropiada gobernabilidad democrática.

\section{Democracia y Modernización del Estado.}

Si bien la democracia formal y representativa está incorporada como un valor en nuestra cultura política latinoamericana, el problema radica en que los gobiernos democráticos no han logrado ofrecer un nivel de bienestar aceptable a todos los sectores de la población ni resolver los problemas del desarrollo, lo cual genera frustración y crisis de credibilidad en el sistema democrático.

La llamada "década perdida" (la de los años 80) para América Latina, lo fue más que todo desde el punto de vista del desenvolvimiento económico. En cambio, la región experimentó un proceso paralelo de retorno a la democracia, por la vía de procesos electorales que significaron la recuperación de la confianza en las instituciones democráticas.

3 Fernando Carrillo Flórez: "El déficit de la democratización en América Latina", en el libro colectivo: Democracia en déficit. Gobernabilidad y Desarrollo en América Latina y el Caribe, Banco Interamericano de Desarrollo, Washington, D.C. 2001. 


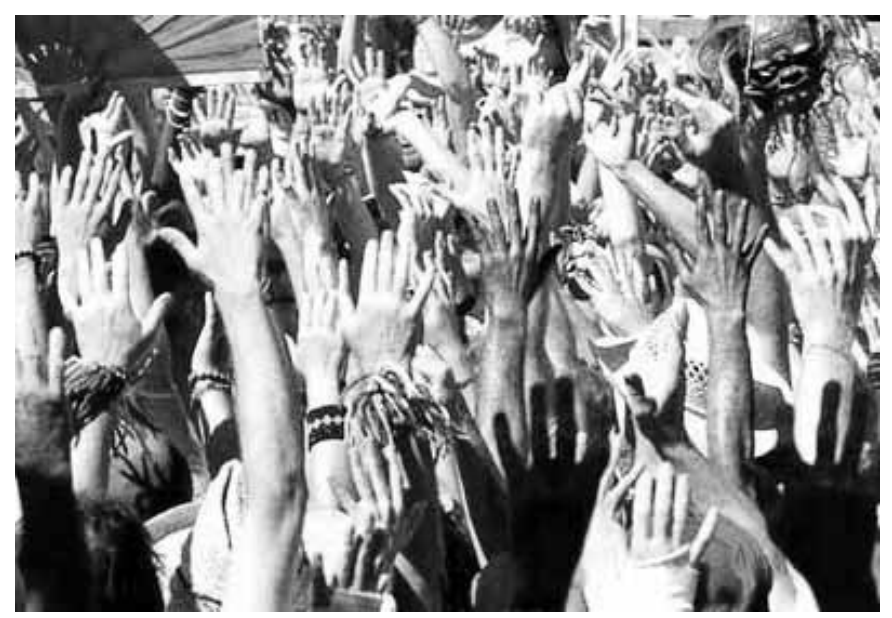

http://comunicaziones.blogspot.com/2010/03/la-cohesion-social-para-el-desarrollo.html

El reto que nuestros países enfrentan, de cara al siglo XXI, es fortalecer las instituciones democráticas como soporte indispensable para su ingreso en la modernidad. Nuestra historia reciente registra la paradoja de un avance en el camino democrático y un estancamiento, cuando no un franco retroceso, en la economía y en los niveles de vida de las grandes mayorías de la población. Esta situación lleva a Francisco Weffort a preguntarse: “¿Está la democracia en América Latina condenada a tener como compañera no a la modernidad sino a la decadencia?". Si en la sociedad se arraiga el sentimiento de que en ella prevalece una gran desigualdad social, es difícil que se genere la estabilidad que la gobernabilidad democrática y el desarrollo humano sustentable requieren. Tiene que existir una cierta "sensación de equidad social", señalan los analistas, para que la gobernabilidad no esté sometida al riesgo constante de la polarización y el estallido social.

La democracia política necesita para sobrevivir que las políticas económicas y las políticas sociales estén estrechamente unidas, integradas. Mejor dicho, que formen parte de un solo esfuerzo nacional. Una mayor equidad social incrementa las posibilidades de fortalecimiento democrático. En la actualidad, los estudios demuestran que América Latina es la región del mundo donde prevalece la mayor desigualdad social. En promedio, la distancia entre el $20 \%$ de la población más pobre y el $20 \%$ de la población más rica es de casi diez veces; en cambio, en los países industrializados esa relación es de seis, y en los países asiáticos de siete (Lechner, 1992). La aplicación de los planes de ajuste macroeconómicos, sin correctivos sociales, incrementó esa desigualdad. El siglo XX, dice Enrique Iglesias, no pudo resolver el problema de la pobreza y la desigualdad por la debilidad en el funcionamiento de los sistemas políticos. Viene a propósito la frase de Juan Somavía: “No es justo equilibrar las cifras macroeconómicas a costa de desbalancear la vida de las gentes".

En cifras redondas, el $40 \%$ de la población de América Latina y el Caribe, vive por debajo de la línea de pobreza (200 millones de seres humanos) y de ellos aproximadamente 125 millones viven en extrema pobreza, o sea con ingresos inferiores a dos dólares por día. El 10\% de los hogares más ricos perciben el $40 \%$ del P.I.B. total. El $40 \%$ de la población económicamente activa trabaja en el sector informal de la economía.

La idea de pobreza está indefectiblemente asociada a la de carencia de algo. ¿Carencia, de qué? ¿Pobreza, de qué? se pregunta Federico Mayor, ex Director General de la UNESCO, y se contesta: "No solo de los recursos indispensables, de alimentos, de vivienda, de vestidos, de conocimientos. Es también una pobreza de futuro, una pobreza de expectativas. Es, asimismo, una pobreza de participación en lo que constituye el único sistema en el que el diálogo y toda esta reflexión pueden llevarse a cabo, que es el de las libertades públicas y la democracia".

Si bien la economía en general ha experimentado un repunte en los últimos años, según la CEPAL, el último informe del PNUD sobre la pobreza en América Latina señala que este modesto crecimiento económico apenas redujo, según el BID y la CEPAL, en 13 millones el número de pobres. Según la misma CEPAL, el $80 \%$ de los nicaragüenses son pobres y más de la mitad de estos viven en la miseria.

Producto en buena parte de la aplicación de los planes de ajuste estructural y de las políticas de inspiración neoliberal, la situación de las clases medias, medias bajas y bajas ha empeorado significativamente en la región. Según la CEPAL el 16\% de los niños/niñas de América Latina padecen de desnutrición (8.8 millones). El 25\% de la población infantil deserta de la escuela antes de aprobar el 5to grado.

Estos escalofriantes datos mueven a Carlos Fuentes a afirmar, que "algo se está agotando en Latinoamérica: los pretextos para justificar la pobreza. Ni raza, ni clima, ni 
latitud, ni etnia, sirven para dar razón de la existencia de doscientos millones de pobres"... "Los pretextos para justificar la pobreza se están agotando porque se han agotado las ideologías que, desde la derecha o la izquierda, nos prometían paraíso instantáneo". Como conclusión, Carlos Fuentes nos dice que "la desigualdad es el gran baldón de la historia latinoamericana". Ella y la pobreza, agrega, "nos marcan como hierro candente". Cabe señalar que para Carlos Fuentes la educación es la mejor arma para combatir la pobreza, y resume su propuesta en este hermoso párrafo: "Gobernar es poblar", dijo el siglo pasado el pensador argentino Juan Bautista Alberdi. Hoy diría: "Gobernar es educar". El vigor de la América Latina reside en su población. Esa población quiere alcanzar plenamente la dignidad ciudadana. De población a ciudadanía. En este proceso indispensable, la cultura se acercará a la política, la creatividad a la economía y la pobreza a la prosperidad". El promedio educativo de la población de América Latina no llega ni a la educación primaria completa. El 25\% de los niños y niñas de América Latina abandonan la escuela primaria antes de aprobar el quinto grado. No nos extrañe, entonces, que América Latina solo produzca el 6\% de la riqueza mundial y participe con un $4 \%$ en el comercio internacional. Su aporte a la producción científica mundial es mínimo.

La modernización del Estado es un elemento clave de la gobernabilidad democrática. $\mathrm{Si}$, como se ha visto, una de las causas de las situaciones de ingobernabilidad se ciñe a la inadecuación de las actuales estructuras estatales y su desborde por las demandas que plantea la sociedad, el rediseño del Estado aparece como uno de los retos fundamentales que nuestros países tienen que enfrentar para mejorar las posibilidades de gobernabilidad.

¿Cuándo un Estado es moderno? Sergio Boisièr nos dice que "un Estado es moderno en tanto sea capaz de comprender la estructura de su entorno, en tanto sea capaz de actuar en forma consonante con la forma de actuar del entorno y en tanto sea capaz de construir un futuro".

Los procesos de globalización y de interdependencia han puesto en crisis el rol del Estado y el concepto mismo de soberanía nacional. El auge de las corrientes neoliberales estimuló la tendencia a reducir el papel del Estado y a fortalecer el mercado. A su vez, los procesos de descentralización significaron otra forma de disminuir las atribuciones del Estado central.

De esta suerte, el Estado aparece, como lo ha señalado Jacques Delors, disminuido por lo alto y por lo bajo: "La globalización de la economía mundial, que tira hacia arriba, y la descentralización y regionalización, que tira hacia abajo, son las dos fuerzas entre las que se encuentran actualmente los Estados-nación". Pero, el Estado es el ámbito idóneo para que los ciudadanos sepan donde están sus derechos y deberes. Sin perjuicio de dar su lugar propio al mercado, al Estado, sigue siendo una intermediación necesaria. El mercado también lo necesitamos, pero no puede ser el único horizonte de una sociedad. "El mercado, nos dice Octavio Paz, es un mecanismo, y como todo mecanismo no tiene conciencia". El Estado nacional moderno tiene que ser funcional: hacia adentro, vía descentralización (microsoberanía) y hacia afuera, vía su incorporación a los procesos de integración regional y subregional (macrosoberanía). Algunos hablan de una doble apertura: la externa, empujada por la globalización y la interna promovida por la descentralización.

Nos parece que al abordar este tema, es necesario colocarlo en una perspectiva correcta y dentro de sus justas proporciones. Si bien existe en América Latina un consenso acerca de la necesidad de reformar el Estado, hay diversas maneras de examinar el problema. Cabe advertir que no debe confundirse modernización del Estado con privatización.

El primer aspecto que conviene definir es el rol mismo del Estado en la sociedad contemporánea, sus funciones actuales, su estructura y la dimensión del aparato estatal, todo dentro de una perspectiva de gobernabilidad democrática y una visión de la sociedad global y del nuevo papel que juega la sociedad civil organizada. $\mathrm{Al}$ respecto, los analistas señalan que para decidir la naturaleza de la reforma y el redimensionamiento del Estado es preciso definir, de previo, el grado de intervención del sector público en las políticas sociales, el equilibrio o balance entre los poderes y el mayor o menor grado de desconcertación o descentralización.

Reformar el Estado para hacerlo más funcional, no significa simplemente reducirlo. La modernización estatal no se limita al redimensionamiento del Estado. 
Se trata, más bien, de redefinir el papel del Estado y hasta podríamos decir, de reinventarlo para hacerlo más adecuado a sus nuevas funciones de cara al siglo XXI. Siendo, como lo es, un producto histórico, el Estado tiene que adaptarse al ritmo de los tiempos y a los nuevos paradigmas económicos, tecnológicos y socioculturales. Entonces, como dice Norbert Lechner, investigador de FLACSO, "la cuestión no es menos Estado o más Estado, sino otro Estado. Es una falacia contraponer Estado y mercado; a ambos los necesitamos. Lo que hay que resolver es la relación entre regulación estatal y dinámica económica".

La reforma del Estado es una necesidad impostergable en nuestros países. Con Estados ineficientes no es posible ejecutar con éxito las indispensables reformas económicas y sociales capaces de promover una auténtica gobernabilidad democrática. Pero el proceso debería abordarse de manera gradual e integral, de suerte que abarque todos los poderes del Estado, pues de nada serviría promover "enclaves de modernidad" en océanos de estructuras arcaicas. La gobernabilidad democrática prioriza en su agenda la reforma del Estado.

El papel estratégico del Estado, como generador de políticas de largo plazo que promuevan la equidad social, obliga a mejorar la calidad del Estado y a introducir la cultura de la visión prospectiva, la planificación estratégica y la evaluación permanente de sus actividades.

La redefinición del Estado debe también conducir a una relación más constructiva con la sociedad civil, con la cual puede redistribuir tareas, pero sin que el Estado se transforme en un cautivo del mercado ni del sector empresarial. Las funciones claves del Estado, su rol facilitador, compensador y promotor de la equidad y la solidaridad social no pueden privatizarse. Pero con un Estado ineficiente es difícil abogar por una mayor inversión social.

No se trata, entonces de escoger simplemente entre un Estado más grande o más pequeño, ni de sustituir el Estado por el mercado. La opción que se impone es un Estado diferente, de calidad, inteligente, con capacidad para diseñar e implementar las políticas y estrategias de desarrollo humano sustentable; más eficiente en la gestión de la cosa pública y más responsable ante sus ciudadanos. En otras palabras, un Estado Moderno, capaz de promover consensos que sirvan de base a políticas de largo aliento, es decir, "políticas de Estado" que trasciendan el tiempo de duración, de por si limitado, de los gobiernos.

Estas políticas son especialmente necesarias en el sector social, a fin de asegurarles la continuidad indispensable para su eficacia. Hoy día, como dice un informe del PNUD, "el Estado Nacional es demasiado pequeño para las grandes cosas y demasiado grande para las pequeñas".

El fortalecimiento de la sociedad civil obliga a una redefinición de sus relaciones con el Estado. La antinomia Estado vs. Sociedad Civil es una antinomia falsa y peligrosa, como advertimos antes. La expresión "sociedad civil" no es nueva. Antecedentes remotos los podemos encontrar incluso entre los filósofos clásicos griegos. Así, para Aristóteles la sociedad civil es la sociedad natural, pues el ser humano (zoom politikon) es por naturaleza gregario y tiende a vivir en comunidad (polis).

Por el contrario, para Thomas Hobbes el estado de naturaleza o sociedad natural es el caos y la anarquía, donde el "hombre es lobo del hombre". Para salir de tal estado, los seres humanos pactaron la creación de la sociedad civil, es decir, "la sociedad civilizada", o Estado.

El concepto moderno de sociedad civil se remonta a Marx, quien contrapuso la noción de sociedad civil a la del Estado. La sociedad civil la identifica con el ámbito donde se generan las relaciones que dan forma a las estructuras económico-sociales. El Estado es, en cambio, el ámbito de las superestructuras políticas y jurídicas.

¿Qué se entiende actualmente por sociedad civil? Hoy en día prevalece un criterio amplio, de suerte que la sociedad civil no sólo es el mundo de las organizaciones no-gubernamentales ni se reduce al sector empresarial. Es eso y mucho más: las asociaciones de defensa de los derechos humanos, las de profesionales, de jóvenes y mujeres organizadas, las cívicas e incluso los mismos partidos políticos. En una palabra: todo lo que no es el Estado, sin que esto signifique necesariamente contraposición. 
La antinomia Estado versus Sociedad Civil debe ser superada por la vía del diálogo y la búsqueda de grandes consensos sociales, que los involucre a ambos y sirvan de base al diseño de políticas y estrategias de largo plazo, que trasciendan la duración de los gobiernos. De esta manera es posible promover una relación más constructiva entre la sociedad civil y el Estado y, por ende, una mejor gobernabilidad democrática.

No es cierto que basta disminuir el rol y el tamaño del Estado y desarrollar el mercado para que haya una mayor equidad y se fortalezca la democracia. Lo cierto es que el repliegue del Estado de una serie de áreas sociales ha producido mayor desigualdad y pobreza en muchos países.

Un Estado moderno, reformado y descentralizado en su estructura y redimensionado en sus funciones implica varias cuestiones, entre ellas, la estructuración de un sistema de partidos políticos fuerte, inclusivo y representativo, en que éstos sean capaces de generar coaliciones mayoritarias estables y de jugar lealmente los papeles de gobierno y oposición, reemplazando la tendencia tradicional de absorción o eliminación del "otro" por la negociación y concertación. Ello suponecrear mecanismos institucionales de democratización interna de los partidos y asegura un sistema de financiamiento público y transparente. Un buen sistema de elecciones primarias internas en los partidos políticos contribuiría

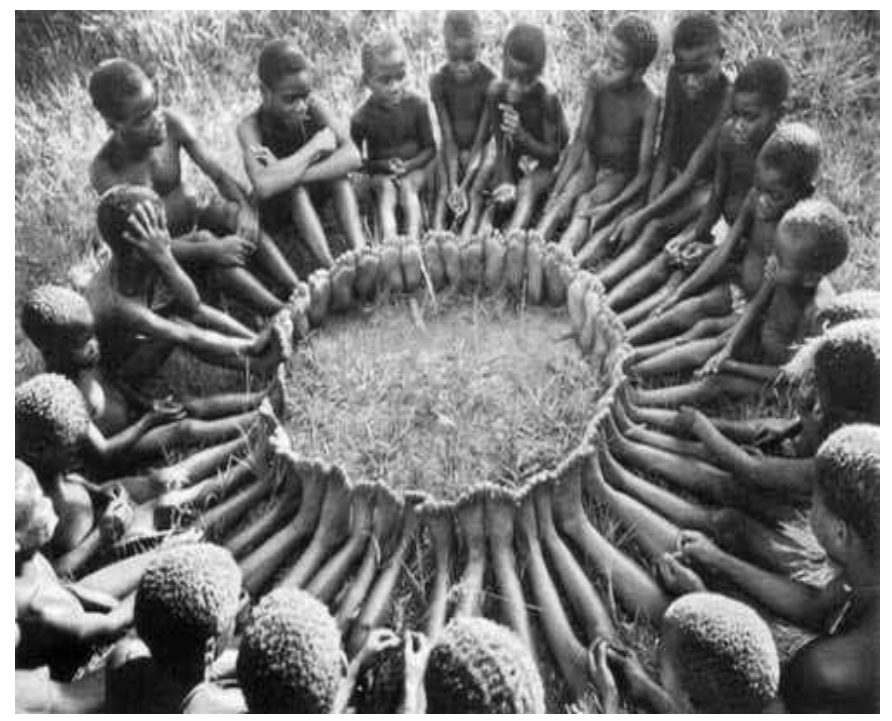

http://cursoseducacion.com a su democratización. La democracia representativa demanda partidos políticos que abandonen las prácticas autoritarias y caudillescas y practique en su seno una auténtica democracia.

Se requiere también reformar y fortalecer el Poder Judicial, pues una administración de justicia corrupta o complaciente es el primer paso a la impunidad y la impunidad es la madre de todas las calamidades. Decía don Pablo Antonio Cuadra: "Cuando la justicia se pervierte, la belleza es condenada a muerte". Con un Poder Judicial altamente partidarizado y proclive a la corrupción no es posible edificar una gobernabilidad democrática.

A su vez, un Estado y un sistema de partidos organizado, exigen una sociedad civil autónoma y fuerte, es decir, actores sociales dotados de capacidad de acción no dependientes del Estado y los partidos, pero en vinculación con ellos.

El conjunto de transformaciones señaladas, que representan los desafíos a la gobernabilidad democrática en América Latina, deben ir acompañadas de un cambio en la cultura política, tanto de dirigentes como de ciudadanos. En primer lugar, se hace necesario un profundo proceso de educación política en todos los niveles, que incremente los niveles de racionalidad y comprensión colectiva en cada nación. En segundo lugar, hay que advertir contra el riesgo que el término de las políticas ideologizadas que amenazaban con la polarización y el fanatismo lleve a una concepción puramente instrumental de la política que deja de preocuparse por la sociedad y sólo busque la realización de intereses particulares. La pérdida de valores y aspiraciones generales de la sociedad, de lo que debería ser el verdadero debate ideológico, puede llevar al triunfo del fin que justfica todos los medios, a la corrupción o al alejamiento de la vida política por parte de la población que siente que ella no tiene nada que ver con sus vidas y problemas. Mantener la preocupación que hoy existe en la gente por "lo político" y evitar que ella desaparezca, exige reformular la actividad política y devolverle a ésta su dimensión ética. 


\section{Ética y Política.}

Esto nos lleva a examinar las relaciones entre la ética y la política.

La tesis de que la Política es una actividad ajena a la moral, donde lo único que cuenta es el acceso al poder, es rechazada hoy día por los politólogos más sobresalientes, convencidos de que la política debe estar regida por la ética y que su fin último no es el poder por el poder mismo sino el bien común. En América Latina y el Caribe se hace necesario promover una nueva cultura política basada en la interdependencia entre lo ético y lo político, entendiendo a la ética no sólo como un conjunto de principios y valores sino como un elemento dinámico, movilizador del comportamiento político de nuestros pueblos.

La revalorización ética de la política llevaría a la ciudadanía a recuperar la credibilidad en la política como una actividad cuyo fin último es promover el bien común. El político debe promover la ética en todo lo que atañe a la sociedad, a partir de su propia transformación ética, su propio cambio. Así se transformaría en un ejemplo de lo ético para la sociedad de la cual forma parte. La función del político es servir. Elegir el camino de la política es elegir el camino del servicio.

Si bien la acción política busca alcanzar el poder, cuando ella está inspirada en principios éticos la búsqueda del poder no se agota en el poder mismo sino en la capacidad de dar respuestas a las demandas de la ciudadanía, en el contexto del pleno respeto a los derechos humanos.
A pesar de la importancia que el Estado tiene en la vida económica y social, no cabe duda que la iniciativa privada, y concretamente los empresarios, han adquirido una gran preponderancia no sólo en lo económico, sino en su ineludible responsabilidad social. Hoy no basta con ser eficiente, se requiere además un comportamiento ético. De esta suerte, se perfila una ética empresarial, para la cual no puede ser indiferente lo que ocurre en la propia empresa o en su entorno. Esta ética empresarial debería, incluso, aplicarse a la acción de las transnacionales que son capaces de producir descalabros financieros en los países en desarrollo. Se requiere, entonces, una "globalización regulada" que impida que el capital transnacional genere desequilibrios que afecten a las sociedades.

La formación ética del ciudadano debe iniciarse en el seno de la familia y debe ser uno de los objetivos fundamentales de la educación. Es en el aula donde se gesta la educación para una ciudadanía consciente y activa. Todo esto demanda incorporar en los sistemas educativos de la región la formación en valores, mediante métodos pedagógicos que no se limiten a la simple transmisión de principios sino que, además, susciten la formación de conductas éticas.

Si bien se reconoce que la corrupción es, en parte, un problema cultural, que es preciso erradicar a través de la reincorporación en los sistemas educativos de contenidos de formación ética del ciudadano, el sistema jurídico debe contribuir a su control y sanción mediante una adecuada legislación. Pero también es preciso fortalecer la administración de la justicia, ya que la impunidad es la madre de todas las calamidades.
La relación entre ética y política, no sólo atañe a quienes ejercen el poder desde los órganos del Estado sino también a los partidos políticos, empresarios, comunicadores sociales y a la ciudadanía en general, desde luego que todos participan en la política o sus acciones pueden tener impacto político. No es válida la dicotomía entre una ética pública y otra privada. La ética pública y la ética privada deben responder a un mismo referente valórico. Debe existir una sola ética. De esta suerte, es tan antiético el que corrompe como el que se deja corromper.

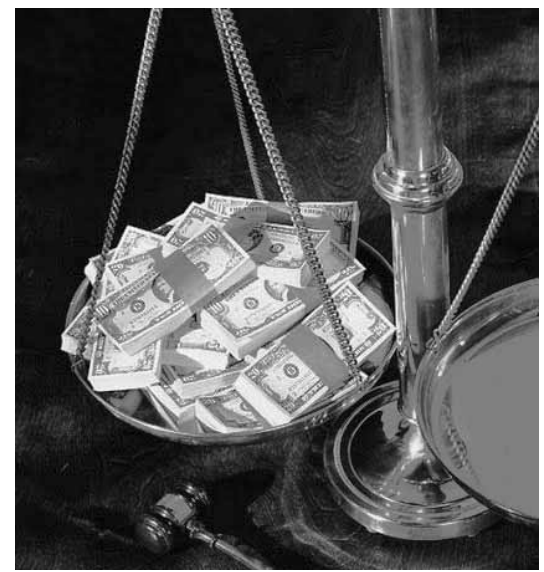

http://mundojuridico1.blogspot.com
Pero la corrupción tiene una consecuencia más de fondo: carcome las raíces mismas de las instituciones democráticas. De ahí que se le tenga como un auténtico cáncer, que destruye las células vivas de la democracia. Alguien ha dicho que la corrupción es "el lobo de la democracia". No es posible concebir una verdadera gobernabilidad democrática cuando la impunidad es la recompensa de la corrupción pública o privada. 


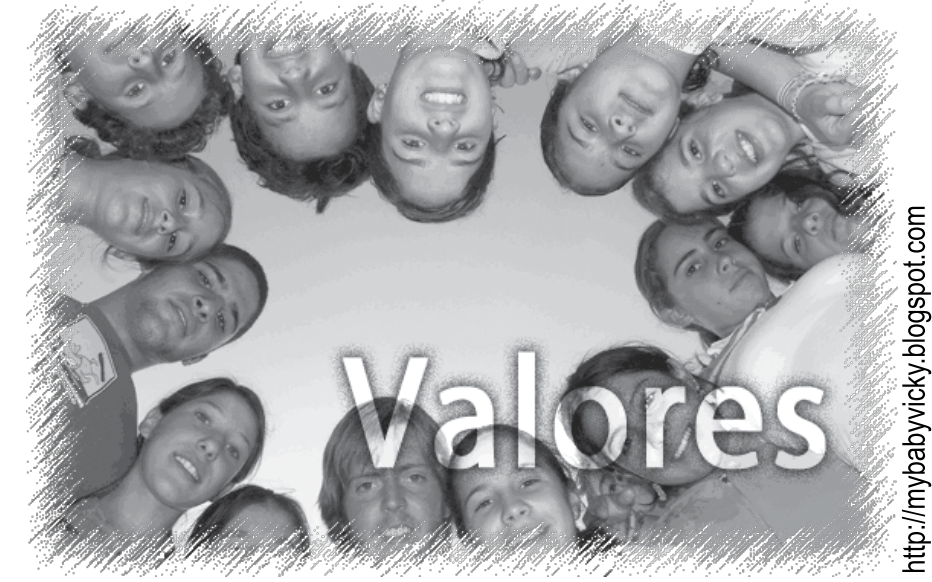

Además, el efecto destructor de la corrupción mina la confianza de los pueblos en el sistema democrático, pues éstos ven frustradas, o mejor dicho defraudadas, las esperanzas que depositaron en las elecciones democráticas de autoridades. Tal sucede cuando aquéllos que fueron electos por el pueblo, en vez de dedicar todas sus energías a resolver los problemas del país o del municipio, tal como lo prometen en sus campañas electorales, utilizan el cargo para enriquecerse, para valerse de su posición para tener acceso al uso privado de los bienes del Estado, o para competir deslealmente con el sector privado.

Un estudio de Guillermo O'Donnell nos revela que el 66\% de los encuestados en toda América Latina tiene poca o ninguna confianza en el Poder Judicial y el $60 \%$ tiene la percepción de que los funcionarios públicos son corruptos.

La falta de credibilidad y confianza en las instituciones y poderes del Estado erosiona y debilita la democracia. Debemos denunciar los dobles discursos y la falta de transparencia en las propuestas políticas y la práctica de los políticos. En Nicaragua se vuelve un imperativo moral promover una nueva cultura política basada en la interdependencia entre lo ético y lo político, entendiendo a la ética no sólo como un conjunto de principios y valores, sino como un elemento dinámico y movilizador del comportamiento político de nuestros pueblos.

La revalorización ética de la política llevaría a la ciudadanía a recuperar la credibilidad en la política como una actividad cuyo fin último es promover el bien común. El político debe promover la ética en todo lo que atañe a la sociedad, a partir de su propia transformación ética, su propio cambio. Así se transforma en ejemplo de lo ético para la sociedad de la cual forma parte. La función del político es servir. Elegir el camino de la política es elegir el camino del servicio.

La relación entre ética y política no sólo atañe a quienes ejercen el poder desde los órganos del Estado sino también a los partidos políticos, empresarios, comunicadores sociales y a la ciudadanía en general, desde luego que todos participan en la política o sus acciones pueden tener impacto político. No es válida la dicotomía entre una ética pública y otra privada. La ética pública y la ética privada deben responder a un mismo referente valórico.

Escribe Bernard Crik, profesor de Ciencias Políticas de la afamada Escuela de Economía de Londres, en su ya clásica obra "En defensa de la política": "La política merece grandes elogios. Es una preocupación de hombres y mujeres libres y su existencia es una prueba de libertad. El elogio en labios de hombres y mujeres libres es valioso, pues es el único que no adolece de servilismo o condescendencia. La política merece ser elogiada como "ciencia" o actividad social que aspira al bien de todas las otras "ciencias" o actividades sin ánimo de destruir ninguna y cultivándolas todas hasta el punto que cada una de ellas permita. La política es creadora de civilización".

Pero, agregamos nosotros, para que la política merezca estos elogios necesariamente tiene que ir de la mano de la ética.

\section{BIBLIOGRAFÍA}

Carlos Mateo Balmelli: Gobernabilidad Democrática, Fundación Konrad Adenauer, Asunción, Paraguay, 1998.

Carmelo Angulo: Desafíos de la gobernabilidad democrática en Nicaragua, en El PNUD y Nicaragua ante el Tercer Milenio. Una visión nicaragüense sobre gobernabilidad y desarrollo humano, PNUD, 2001.

FernandoCarrilloFlórez: "Eldéficitdela democratización en América Latina", en el libro colectivo: Democracia en déficit. Gobernabilidad y Desarrollo en América Latina y el Caribe, Banco Interamericano de Desarrollo, Washington, D.C. 2001. 